\title{
Pancreatic remnant fate
}

\author{
S. Hać ${ }^{1}$, J. Pieńkowska ${ }^{2}$, I. Madejewska ${ }^{1}$, D. Łaski ${ }^{1}$, J. Kostro ${ }^{1}$, P. Mroczkowski ${ }^{3}$, \\ M. Studniarek ${ }^{2}$, Z. Śledziński ${ }^{1}$ \\ ${ }^{1}$ Department of General Endocrine and Transplant Surgery, Medical University of Gdansk, Poland \\ ${ }^{2}$ Department of Radiology Medical University of Gdansk, Poland \\ ${ }^{3}$ Department of Visceral and Vascular Surgery, University of Magdeburg, Germany
}

Received 1 July 2014; Accepted 13 July 2014]

There is eternal discussion on the best surgical method of pancreatoduodenectomy and reconstruction method. Several different methods of pancreatic stump anastomosis exist. The most popular argument taken into account in the discussion is the frequency of early postoperative complications. Relatively fewer papers analyse the late functional outcome of pancreatic surgery and the method of anastomosis employed. Authors presented short series of 12 patients after pancreatic surgery with analysis of pancreatic remnant morphology and function. Pancreatic remnant volume, pancreatic duct distension and stool elastase-1 test were analysed. There was no correlation of pancreatic exo- or endocrine insufficiency with the volume of pancreatic remnant or the kind of surgery or anastomosis performed. (Folia Morphol 2015; 74, 1: 56-60)

Key words: pancreatic resection, pancreatic surgery, pancreatic exocrine function, digestive tract

\section{INTRODUCTION}

Pancreatoduodenectomy (PD) is the procedure with 100 years history and is accepted as treatment of choice in pancreato-biliary area malignancies [12]. The pancreas is composed of two embryo buds resulting in complicated configurational anatomy of pancreatic duct [8]. Many investigations are carried out analysing anatomical, technical, physical and histological factors related to complications of pancreatic anastomosis. Simultaneously discussion of superiority of technical variants of operation is ongoing. A large effort is made to find the best management. Short time efficacy of surgery is measured usually by means of complications and mortality rate after PD $[18,19,28]$. The large series indicate the influence of parenchyma texture, pancreatic duct size, intraoperative blood loss and patient comorbidity $[1,7,11,22,24]$. The late outcome of PD is monitored by oncological results and quality of life. The objective of pancreatic remnant condition is established on the basis of pancreatic function preservation and imaging criteria $[16,24,27]$. Several investigators supposed to find the correlation between the technique of pancreatic remnant anastomosis and its function $[9,16,27]$. The reduction of glandular tissue, pancreatic remnant duct patency, deficiency of duodenal stimulation to pancreas and inactivation of pancreatic enzymes are considered important factors of maldigestion related to pancreatic function [24]. The pancreatic remnant duct dilatation in postoperative course is thought to be the symptom of progressive remnant damage or outflow obstruction related to anastomosis method or technique [27].

\section{MATERIALS AND METHODS}

The study protocol was approved by Local Ethic Committee of Medical University of Gdansk, Poland

Address for correspondence: S. Hać, MD, PhD, Department of General Endocrine and Transplant Surgery, Medical University of Gdansk, ul. Dębinki 7, 80-952 Gdańsk, Poland, tel: +48 58349 3029, e-mail: sthac@gumed.edu.pl 
(No NKEBN/485-236/2009). Twelve patients after PD were identified in outpatient clinic. All participants signed informed consent to participate in the study according to the protocol. The mean patients' age was 66.3 (from 43 to 77 ) years, the male-female ratio was 8:4. Patients underwent PD from 3 to 86 (mean 36.6) months prior to the enrolment. The primary diagnosis, treatment administrated, weight maintenance, body mass index (BMI) are summarised in Table 1. Eight patients underwent standard Whipple resection with pancreatogastrostomy $(\mathrm{PG}), 4$ underwent pylorus preserving pancreatic head resection with side-to-side pancreatojejunostomy (PP-PJ).

Pancreatic malfunction history and stool elastase- 1 test concentration based on ELISA method (Cat. No: 07, ScheBo Stool Test, Giessen, Germany) was performed. Stool samples were obtained during normal feeding period using E1-Quick-Prep tube (Cat. No: 07-Quick, ScheBo Stool Test, Giessen, Germany). Patients did not receive proton pump inhibitors and did not discontinue enzyme supplements, according to manufacturer information.

Three-phase (arterial, pancreatic, and portal venous phases) contrast-enhanced multi detector computed tomography (MDCT) was performed with a 64-slice MDCT scanner (LightSpeed VCT; GE Healthcare) for 6 patients. A dose of $1.0 \mathrm{~mL} / \mathrm{kg}$ body weight of the $300 \mathrm{mgl} / \mathrm{mL}$ nonionic contrast material lohexol (Omnipaque, GE HEALTHCARE AS, Norway) was administered intravenously at a rate of $3 \mathrm{~mL} / \mathrm{s}$ by means of a power injector (Auto Enhance A-50; Nemoto Kyorindo, Tokyo, Japan). The scanning delay was individually determined with a test bolus injection technique. Pancreatic phase images were obtained after scanning of the arterial phase imaging during a single breath hold with an interscan delay $10 \mathrm{~s}$. The mean injection to scan delay for arterial phase imaging was $21.7 \mathrm{~s}$ and that for pancreatic phase imaging was $33.7 \mathrm{~s}$. The example of image is shown on Figure 1.

For the subsequent imaging analysis, the pancreatic phase images of $2.5-\mathrm{mm}$ collimation obtained with 64 -slice MDCT. From these axial images of $0.625-\mathrm{mm}$ to 2.5 -mm slice thickness, oblique-coronal multiplanar reconstruction (MPR) images of $0.7-\mathrm{mm}$ slice thickness were generated at $0.7-\mathrm{mm}$ intervals on a computer workstation (Advantage Workstation 4.4; GE Healthcare) by broad-certified radiologist who was the study coordinator. All data were compared to the situation prior to the surgery is available. Pancreatic

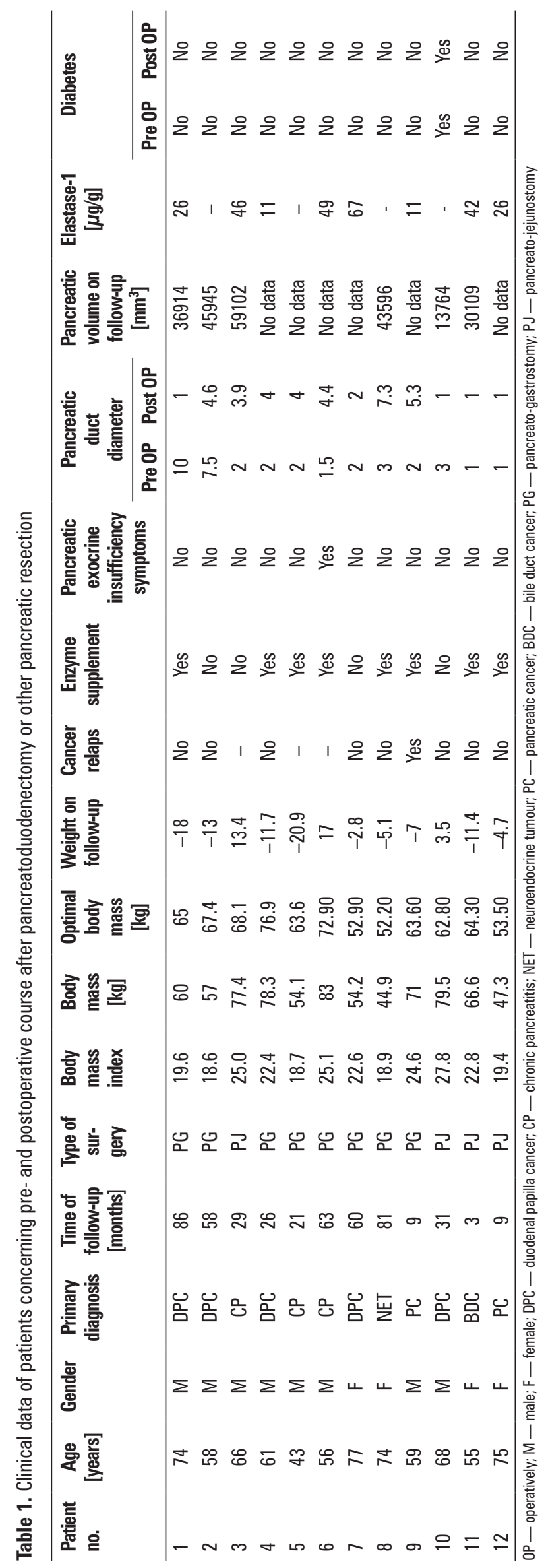




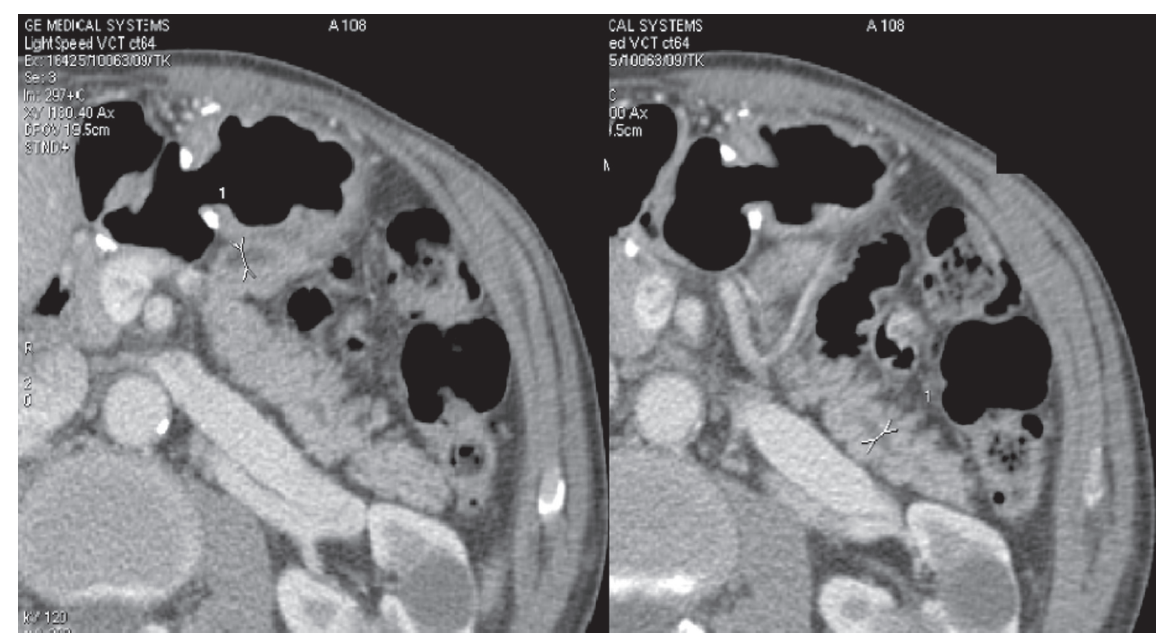

Figure 1. Pancreatic remnant duct identification and measurement on computed tomography scan (pancreatic duct is indicated between arrows).

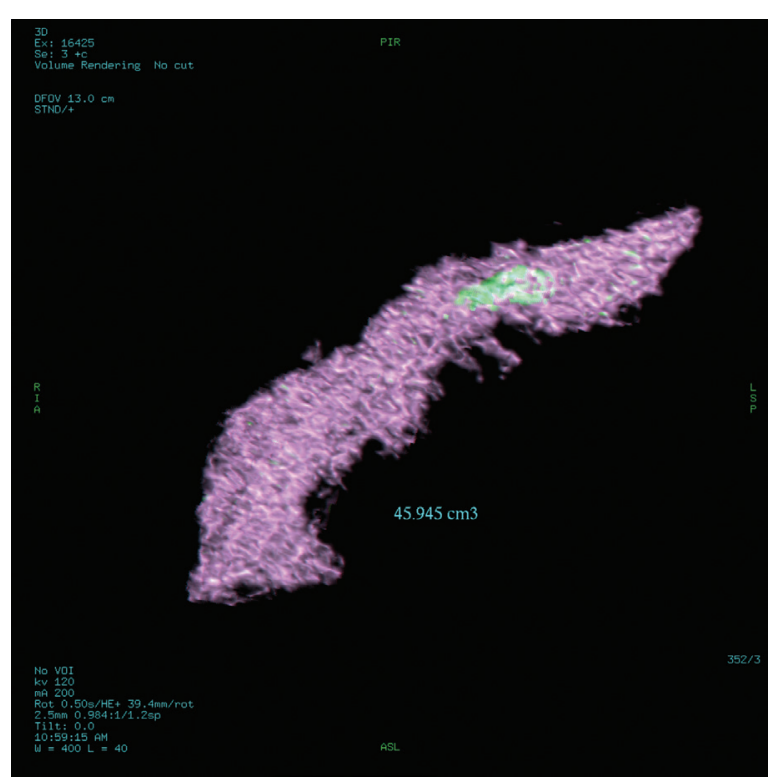

Figure 2. Pancreatic remnant volumetry as the result of computed tomography digital processing.

remnant was digitally measured, pancreatic volumetry (Fig. 2) as well as pancreatic duct diameter at the anastomosis and proximal to it.

\section{RESULTS}

Nine of twelve patients underwent MDCT without intolerance and all scans quality was suitable for analysis. Nine patients decline contrast enhanced $\mathrm{CT}$ and accept only standard examination. From this reason only limited morphological data are available in that group. Pancreatic duct mean diameter before surgery was $1.93 \mathrm{~mm}(1-10 \mathrm{~mm})$. On follow up the mean size of pancreatic remnant duct diameter was $3.14 \mathrm{~mm}$. Three patients with distended pre operatively pancreatic duct presented marked diameter reduction (patient no. 1, 2 and 10). Seven patients has increased pancreatic remnant duct diameter, the other 3 did not presented diameter enlargement. Three of four patients after PJ did not presented pancreatic remnant duct distension. The pancreatic parenchyma and duct contain calcifications only in patient no. 15. There was no chronic opioids consumption in analysed group. Patient does not present history of pancreatic exocrine and endocrine malfunction. Three patients have gain weight postoperatively, other 9 have weight loss from 2.8 to $20.9 \mathrm{~kg}$. Patients BMI post operatively vary from 18.6 to $27.8 \mathrm{~kg} / \mathrm{m}^{2}$ and was qualified as well-nourished or obese (3 patients had BMI more than $25 \mathrm{~kg} / \mathrm{m}^{2}$ ). Detailed dietary information did not revealed symptoms of pancreatic exocrine malfunction. Elastase-1 stool concentration and morphologic data are summarised in Table 1. There was no correlation between elastase- 1 stool concentration and pancreatic remnant volume or pancreatic remnant duct diameter.

\section{DISCUSSION}

The biology of pancreato-biliary malignancy resulted in limited number of patients suitable for long term follow-up.

Early outcome after PD is monitored with pancreatic fistula rate, morbidity and postoperative mortality. During last two decades considerable progress was achieved in pancreatic surgery and complication rate significant reduction. No randomised controled trial 
is available on the superiority of PG or PJ concerning early postoperative outcome and complications rate $[2,3,5,6]$. Some studies documented fewer postoperative pancreatic fistula rates after PG $[16,21]$.

Uncomplicated PD resulted in several inconvenience for the patient after recovery. Some of them are the results of new configuration of digestive tract, food intake limitation, dietary restriction, intolerance and malabsorption. The other relatively late problem after PD is pancreatic exo- and endocrine malfunction. The reason of pancreatic exocrine insufficiency is thought to be the pancreatic glandular tissue deficit, remnant duct occlusion or permanent pancreatic enzyme inactivation in the stomach acid environment [17]. There are data confirming the time dependent pancreatic duct dilatation within few months after PD $[24,27]$. The pylorus preserving PD is thought to be beneficial concerning lower risk of postoperative dumping syndrome and stomal ulceration [23]. Some experimental data confirm the difference in the pancreatic remnant changes after different anastomosis technique applied [4]. The most data support the beneficial use of duct-to-mucosa PJ $[4,27]$. This technique gives the best opportunity to control the patency of pancreatic duct during surgery and gives perfect adaptation of mucosa-to-mucosa resulting in the lowest risk of late scar stricture $[10,28]$.

Our series revealed, similarly to some other authors, more frequent increase of pancreatic remnant duct diameter after PG comparing with PJ. This observation did not correspond to clinical manifestation of pancreatic exocrine insufficiency.

Some authors document no significant differences of pancreatic exocrine insufficiency, nutritional status, gastric emptying and pancreatic duct diameter [9]. However the diameter of pancreatic duct before the operation and on follow-up increased in both PJ and PG group in some series. Jang et al. [16] evaluated pancreatic exocrine function after PJ vs. PG and noticed severe exocrine insufficiency after later operation with marked pancreatic duct dilatation. However authors use only history and clinical presentation to establish exocrine pancreatic insufficiency. Passaux et al. [24] reported high rate of pancreatic exocrine insufficiency (95\%) after PD and pancreatico-gastro anastomosis on small cohort of patients. Authors use stool elastase- 1 test. In that series the magnetic resonance cholangio pancreatography of pancreatic remnant duct permeability was analysed and all patients presented duct dilatation. The results of pancreatic function tests were in accordance to observed duct patency. Surprisingly, pancreatic remnant duct diameter observed in "patent" group was larger than in "obstructed" one [24].

Similarly, in our series marked elastase- 1 stool concentration decrease regardless of pancreatic anastomosis performed. Surprisingly, patients with low elastase-1 level without enzyme supplement therapy did not presented typical symptoms of pancreatic exocrine insufficiency or malnutrition.

Many cohorts are based on limited number of patients ranging from 19 to $73[9,13,16,20,24-27]$. Surprisingly, the largest series from Hyodo et al. [13] documented negligible pancreatic duct dilatation after PG and no symptoms of exo- and endocrine insufficiency. However, Japan group use clinical criteria of pancreatic exocrine function. Authors described in details PG modification with pancreatic stump invagination and gastric mucosa approximation [13]. This observation on the largest available group might guide the discussion back to technical details and material used to manage pancreato-enteral anastomosis as the detrimental factor of late operatively outcome. The biology of the primary reason for PD resulted in small group of follow-up series. On the other hand, chronic pancreatitis patients after PD are not candidates to be compared because of ongoing inflammatory process of pancreatic remnant and progressive damage resulting in pancreatic function loss. Ishii et al. [14] analysed postoperative pancreatic juice output and exocrine function based on ${ }^{13} \mathrm{C}$-dipeptide-(Bz-Tyr-Ala) breath test after PD. Small group operated with Roux-en-Y reconstruction presented marked difference in pancreatic juice volume and amylase concentration. All patients with primary diagnosis of chronic pancreatitis (CP) and pancreatic cancer (PC) presented significantly lower values than duodenal papillary carcinoma one [14]. All patients with primary PC met also microscopic criteria of CP in the remnant on transection site. The proportion of fibrosis to glandular tissue at pancreatic transaction site of PD performed because of PC ranges from $47 \%$ to $55 \%$ in different series $[15,27]$. Similar result is observer in presented series.

Comparing several data concerning pancreatic remnant function there is no uniform methodology used for exocrine function evaluation thus data seems to be relatively difficult for comparison and interpretation. 


\section{CONCLUSIONS}

Our short series revealed no clinical difference between PG and PJ in follow up.

\section{REFERENCES}

1. Adam U, Makowiec F, Riediger H, Schareck WD, Benz S, Hopt UT (2004) Risk factors for complications after pancreatic head resection. Am J Surg, 187: 201-208.

2. Alexakis N, Halloran C, Raraty M, Ghaneh P, Sutton R, Neoptolemos JP (2004) Current standards of surgery for pancreatic cancer. Br J Surg, 91: 1410-1427.

3. Aranha GV, Hodul P, Golts E, Oh D, Pickleman J, Creech S (2003) A comparison of pancreaticogastrostomy and pancreaticojejunostomy following pancreaticoduodenectomy. J Gastrointest Surg, 7: 672-682.

4. Bai MD, Rong LQ, Wang LC, Xu H, Fan RF, Wang $P$, Chen XP, Shi LB, Peng SY (2008) Experimental study on operative methods of pancreaticojejunostomy with reference to anastomotic patency and postoperative pancreatic exocrine function. World J Gastroenterol, 14: 441-447.

5. Bassi C, Falconi M, Molinari E, Salvia R, Butturini G, Sartori N, Mantovani W, Pederzoli P (2005) Reconstruction by pancreaticojejunostomy versus pancreaticogastrostomy following pancreatectomy: results of a comparative study. Ann Surg, 242: 767-771.

6. Benzoni $E$, Zompicchiatti A, Saccomano E, Lorenzin D, Baccarani U, Adani G, Noce L, Uzzau A, Cedolini C, Bresadola F, Intini S (2008) Postoperative complications linked to pancreaticoduodenectomy. An analysis of pancreatic stump management. J Gastrointestin Liver Dis, 17: 43-47.

7. Buchler MW, Kleeff J, Friess H (2007) Surgical treatment of pancreatic cancer. J Am Coll Surg, 205: S81-S86.

8. Desdicioglu K, Malas MA, Evcil EH (2010) Foetal development of the pancreas. Folia Morphol, 69: 216-224.

9. Fang $W L$, Su CH, Shyr YM, Chen TH, Lee RC, Tai LC, Wu CW, Lui WY (2007) Functional and morphological changes in pancreatic remnant after pancreaticoduodenectomy. Pancreas, 35: 361-365.

10. Hac S, Peksa R, Dobosz M, Wysocki T, Lampe P, Kusnieez K, Mroczkowski P, Sledzinski Z (2012) Pancreatic anastomosis healing. Open J Pathol, 2: 96-101.

11. Henne-Bruns D, Vogel I, Luttges J, Kloppel G, Kremer B (2000) Surgery for ductal adenocarcinoma of the pancreatic head: staging, complications, and survival after regional versus extended lymphadenectomy. World J Surg, 24: 595-601.

12. Howard JM (1999) Development and progress in resective surgery for pancreatic cancer. World J Surg, 23: 901-906.

13. Hyodo M, Nagai H (2000) Pancreatogastrostomy (PG) after pancreatoduodenectomy with or without duct-to-mucosa anastomosis for the small pancreatic duct: short- and long-term results. Hepatogastroenterology, 47: 1138-1141.

14. Ishii $Y$, Kohno T, Ito A, Suzuki S, Kohno T, Takayama T, Asai S (2007) Evaluation of pancreatic exocrine secretion using 13C-dipeptide (benzoyl-L-tyrosyl-[1-(13)C]alanine) breath test: focusing on pancreatoduodenectomy cases. Pancreas, 35: 313-319.

15. Ishii $Y$, Kohno $T$, Ito $A$, Suzuki $S$, Kohno $T$, Takayama $T$, Asai S (2007) Measurement of extra-pancreatic secretory function by 13C-dipeptide breath test. Transl Res, 149: 298-303.

16. Jang JY, Kim SW, Park SJ, Park YH (2002) Comparison of the functional outcome after pylorus-preserving pancreatoduodenectomy: pancreatogastrostomy and pancreatojejunostomy. World J Surg, 26: 366-371.

17. Kahl S, Malfertheiner P (2004) Exocrine and endocrine pancreatic insufficiency after pancreatic surgery. Best Pract Res Clin Gastroenterol, 18: 947-955.

18. Kawarada Y, Das BC, Naganuma T, Isaji S (2001) Surgical treatment of pancreatic cancer. Does extended lymphadenectomy provide a better outcome? J Hepatobiliary Pancreat Surg, 8: 224-229.

19. Kleespies $A$, Albertsmeier $M$, Obeidat $F$, Seeliger $H$, Jauch KW, Bruns CJ (2008) The challenge of pancreatic anastomosis. Langenbecks Arch Surg, 393: 459-471.

20. Konishi M, Ryu M, Kinoshita T, Inoue K (1999) Pathophysiology after pylorus-preserving pancreatoduodenectomy: a comparative study of pancreatogastrostomy and pancreatojejunostomy. Hepatogastroenterology, 46: 1181-1186.

21. McKay A, Mackenzie S, Sutherland FR, Bathe OF, Doig C, Dort J, Vollmer CMJr, Dixon E (2006) Meta-analysis of pancreaticojejunostomy versus pancreaticogastrostomy reconstruction after pancreaticoduodenectomy. Br J Surg, 93: 929-936.

22. Nakamura H, Murakami Y, Uemura K, Hayashidani Y, Sudo T, Ohge H, Sueda T (2009) Predictive factors for exocrine pancreatic insufficiency after pancreatoduodenectomy with pancreaticogastrostomy. J Gastrointest Surg, 13: 1321-1327.

23. Ohtsuka T, Yamaguchi K, Chijiiwa K, Tanaka M (2001) Postoperative pancreatic exocrine function influences body weight maintenance after pylorus-preserving pancreatoduodenectomy. Am J Surg, 182: 524-529.

24. Pessaux P, Aube C, Lebigot J, Tuech JJ, Regenet N, Kapel N, Caron C, Arnaud JP (2002) Permeability and functionality of pancreaticogastrostomy after pancreaticoduodenectomy with dynamic magnetic resonance pancreatography after secretin stimulation. J Am Coll Surg, 194: 454-462.

25. Rault A, SaCunha A, Klopfenstein D, Larroude D, Epoy FN, Collet D, Masson B (2005) Pancreaticojejunal anastomosis is preferable to pancreaticogastrostomy after pancreaticoduodenectomy for longterm outcomes of pancreatic exocrine function. J Am Coll Surg, 201: 239-244.

26. Sho $M$, Nakajima $Y$, Kanehiro $H$, Hisanaga $M$, Nishio $K$, Nagao M, Tatekawa Y, Ikeda N, Kanokogi H, Yamada T, Hirohashi S, Hirohashi R, Uchida H, Nakano H (1998) A new evaluation of pancreatic function after pancreatoduodenectomy using secretin magnetic resonance cholangiopancreatography. Am J Surg, 176: 279-282.

27. Tomimaru Y, Takeda Y, Kobayashi S, Tomimaru Y, Takeda Y, Kobayashi S, Marubashi S, Lee CM, Tanemura M, Nagano H, Kitagawa T, Dono K, Umeshita K, Wakasa K, Monden M (2009) Comparison of postoperative morphological changes in remnant pancreas between pancreaticojejunostomy and pancreaticogastrostomy after pancreaticoduodenectomy. Pancreas, 38: 203-207.

28. Z'graggen K, Uhl W, Friess H, Buchler MW (2002) How to do a safe pancreatic anastomosis. J Hepatobiliary Pancreat Surg, 9: 733-737. 